\title{
Hand/Face Border as a Limiting Boundary in the Body Representation in Monkey Somatosensory Cortex
}

\author{
Paul R. Manger, Timothy M. Woods, Alberto Muñoz, and Edward G. Jones \\ Department of Anatomy and Neurobiology, University of California, Irvine, Irvine, California 92697
}

\begin{abstract}
Horizontal intracortical connections may form one substrate for representational plasticity in somatosensory cortex. Electrophysiological mapping demonstrated the finer details of the representations of the hand, lower jaw, neck, and face in area $3 \mathrm{~b}$ of normal macaque monkeys. Injections of two fluorescent tracers then defined the extent to which horizontal connections crossed from the face into the hand representations and vice versa in area $3 \mathrm{~b}$. Connections are widely distributed within cortical representations of skin areas innervated by cervical nerves or by the trigeminal nerve but do not cross a border defined by the anterior limit of the representation of skin innervated by the second cervical nerve. This border separates the representation of the muzzle, innervated only by the mandibular nerve, and the representation of the lower jaw and neck region,
\end{abstract}

innervated by the second and third cervical nerves but overlapped by the mandibular nerve. Thus, the muzzle representation lacks connections with the hand and with the lower jaw and neck representations, but the representations of the hand and of the lower jaw and neck are strongly interconnected. Overlap of the hand and of the lower jaw and neck representations and of their horizontal intracortical connections may form one basis for expansions of the lower jaw representation into that of the hand when peripheral input from the hand is lost. Lack of connections with the rest of the face representation may limit this spread.

Key words: receptive fields; fluorescent dextrans; horizontal connections; plasticity; mandibular nerve; cervical nerves
The border between the representations of the hand and the face is a landmark in the somatotopic map in area $3 \mathrm{~b}$ of primate somatosensory cortex. The border is not definable architectonically (Powell and Mountcastle, 1959a); the two representations form part of a continuous representation of the contralateral body surface (Woolsey et al., 1942; Dreher et al., 1975; Kaas et al., 1979; Pons et al., 1987).

The physiologically defined hand/face border has formed a focal point in studies of representational plasticity in somatosensory cortex of adult monkeys (Merzenich et al., 1984; Wall et al., 1986; Florence et al., 1994; Garraghty et al., 1994). Garraghty et al. (1994) reported no change in the position of the hand/face border representation in animals that had undergone extensive deafferentation of the hand and in which the representation of the face might have been anticipated to spread into the silenced representation of the hand. Mutability of the hand/face border, however, was reported in monkeys that had undergone unilateral dorsal rhizotomies of all cervical spinal segments 12 years previously (Pons et al., 1991). The representation of the face had expanded by $10-14 \mathrm{~mm}$ into the region of area $3 \mathrm{~b}$ that would have been occupied previously by the representation of the hand. This expansion was too extensive to be accounted for by overlap in thalamocortical projections from the former hand and face representations in the ventral posterior nucleus (VPL) of the thalamus. The spread was attributed to cascading expansions of facial representa-

Received March 21, 1997; revised May 13, 1997; accepted May 27, 1997.

This work was supported by Grant NS 21377 from National Institutes of Health, United States Public Health Service.

Correspondence should be addressed to Dr. E. G. Jones, Department of Anatomy and Neurobiology, University of California, Irvine, Irvine, CA 92697.

Dr. Manger's present address: Neurobiology Research, 151A Sepulveda Veterans Administration Medical Center, 16111 Plummer Street, North Hills, CA 91343.

Copyright (C) 1997 Society for Neuroscience $0270-6474 / 97 / 176338-14 \$ 05.00 / 0$ tions determined by divergence of connections in subcortical centers. Expansion of a part of the head representation normally found medial to the representation of the hand (Woolsey et al., 1942; Dreher et al., 1975) was also suggested as sufficient to account for much of the spread (Lund et al., 1994).

In the reorganized cortex described by Pons et al. (1991), most multiunit responses were obtained by stimulating receptive fields in the vicinity of the lower jaw. In this region of skin, the distribution of the mandibular nerve normally overlaps that of the second cervical nerve (Sherrington, 1939). Therefore, preexisting overlap of the lower jaw and hand representations at cortical and thalamic levels could help explain the extensive plasticity of the cortical maps in these long-term experiments. Overlap in thalamocortical projections of the ventral posterior thalamic nucleus is limited, however, to $\sim 1.5 \mathrm{~mm}$ (Rausell and Jones, 1995). Moreover, in the brainstems and thalami of the chronically deafferented monkeys used in the study of Pons et al. (1991), cells had disappeared from most of the cuneate and from large parts of the VPL thalamic nucleus as the result of transneuronal degeneration (Rausell et al., 1992). Therefore, at cortical levels, overlap and potentially the spread of one part of the representation into another silenced by peripheral denervation may depend on the extent to which horizontal, intracortical connections spread from one representation into the other.

The present results show the detailed somatotopy of the hand/ face border, suggesting redefinition of the border in terms of trigeminal and spinal inputs, and show that few horizontal connections that might serve as a basis for activity-dependent plasticity cross this border.

\section{MATERIALS AND METHODS}

Six macaque monkeys (four Macaca mulatta and two Macaca fuscata), aged 2 years or older, were used. The somatosensory cortex from one 
hemisphere of each monkey was used for physiological recording alone to define the normal representation in the hand/face border region. The somatosensory cortex of the other hemisphere was used for anatomical tracing in conjunction with recording to define the extent to which corticocortical connections crossed this border.

For the connection-tracing part of the study, animals were anesthetized with intramuscular ketamine $(15 \mathrm{mg} / \mathrm{kg})$ and were maintained on intravenous Nembutal administered at a rate of $\sim 5 \mathrm{mg} \cdot \mathrm{kg}^{-1} \cdot \mathrm{hr}^{-1}$. They were placed in a stereotaxic frame, and under sterile conditions, small openings in the skull and dura mater were made to expose a region of the postcentral gyrus opposite the tip of the intraparietal sulcus. Varnish-insulated tungsten microelectrodes ( $5 \mathrm{M} \Omega$ impedance) were advanced at an angle down the posterior bank of the central sulcus in area $3 b$; each track was separated from its neighbor by $\sim 500$ $\mu \mathrm{m}$. Multiunit discharges of neurons at $100-200 \mu \mathrm{m}$ intervals were elicited to light tactile stimulation of the hand and face, and the receptive fields of the neurons were mapped to locate the border between the representations of the hand, face, and adjacent regions. During the mapping session, the cortical surface was kept moist with normal saline. Glass micropipettes having tip diameters of $15-20 \mu \mathrm{m}$ and containing 5\% Fluorescein-dextran or 5\% FluoroRuby (Molecular Probes, Eugene, OR) in $0.1 \mathrm{M}$ phosphate buffer were then introduced along selected electrode tracks $1 \mathrm{~mm}$ or less on either side of the hand/face border and were advanced to coordinates at which receptive fields on the hand or face had been recorded. Positive iontophoretic currents of $8 \mu \mathrm{A}$ were applied through a silver wire for $15-20 \mathrm{~min}$, using a $50 \%$ duty cycle. The animals were allowed to survive for $10-14 \mathrm{~d}$.

After the survival time, the animals were reanesthetized as described above, and the hemisphere opposite that containing the injections was explored electrophysiologically to define the details of the normal hand/ face border representation. A larger craniotomy was made over the part of the postcentral gyrus homotopic to the area which was injected, and the dura mater was removed. An acrylic well was formed around the opening and filled with mineral oil. Fine grain microelectrode maps of the region of area $3 \mathrm{~b}$ in the vicinity of the hand/face border were made, using the same techniques as described above. The distance between electrode penetrations in the hemispheres was usually $<500 \mu \mathrm{m}$, except where blood vessels precluded it. Recordings were made in 100-200 $\mu \mathrm{m}$ steps as the microelectrodes were advanced down the posterior bank of the central sulcus. At the conclusion of the mapping session, the animals were given an overdose of Nembutal and perf used through the ascending aorta with cold, normal saline followed by $4 \%$ paraformaldehyde in $0.1 \mathrm{M}$ phosphate buffer. The brain was removed and blocked, and the blocks were infiltrated with $30 \%$ sucrose at $4^{\circ} \mathrm{C}$. These blocks were subsequently frozen in dry ice.

Blocks of cortex from the hemisphere mapped as the terminal experiment were cut serially at $50 \mu \mathrm{m}$ in the plane of the electrode penetrations, which was approximately parasagittal. This allowed visualization of the length of each electrode track in two or three consecutive sections of cortex. The sections were stained with thionin, and architectonic boundaries were matched to recording sites, using well established criteria (Powell and Mountcastle, 1959a; Roberts and Akert, 1963; Jones et al., 1978). From this, two-dimensional reconstructions showing the somatotopic maps and borders of area $3 \mathrm{~b}$ were generated.

Blocks of cortex from the hemisphere injected with fluorescent dextrans were cut serially at $25 \mu \mathrm{m}$ in the parasagittal plane. Alternating sections were mounted and stained with thionin or were mounted without staining for examination under epifluorescence. Sections for fluorescence microscopy were mounted on clean glass slides, allowed to dry, and then coverslipped in a 3:1 mixture of glycerol and $0.1 \mathrm{M}$ phosphate buffer. These sections were examined using fluorescein and Texas Red exciting filters. The stage of the microscope was attached to optical encoders allowing computer-generated maps of the sections to be made with the Minnesota Datametrics MD 2 plotting system. These maps showed landmarks such as blood vessels, the surface of the cortex, and the border between gray matter and white matter. The locations of the injections (Fig. 1), of anterogradely labeled terminal ramifications, and of retrogradely labeled cells (Fig. 2) were then plotted onto the maps. Camera lucida projections of the alternating thionin-stained sections were then merged with the plottings, directly matching architectonic borders and electrode penetrations with the locations of labeled terminal ramifications and cells in area $3 \mathrm{~b}$ and adjoining areas. Selected sections were scanned in $1 \mu \mathrm{m}$ steps using an MRC 600 dual-channel, dual-laser confocal scanning system and filter blocks that allowed simultaneous or

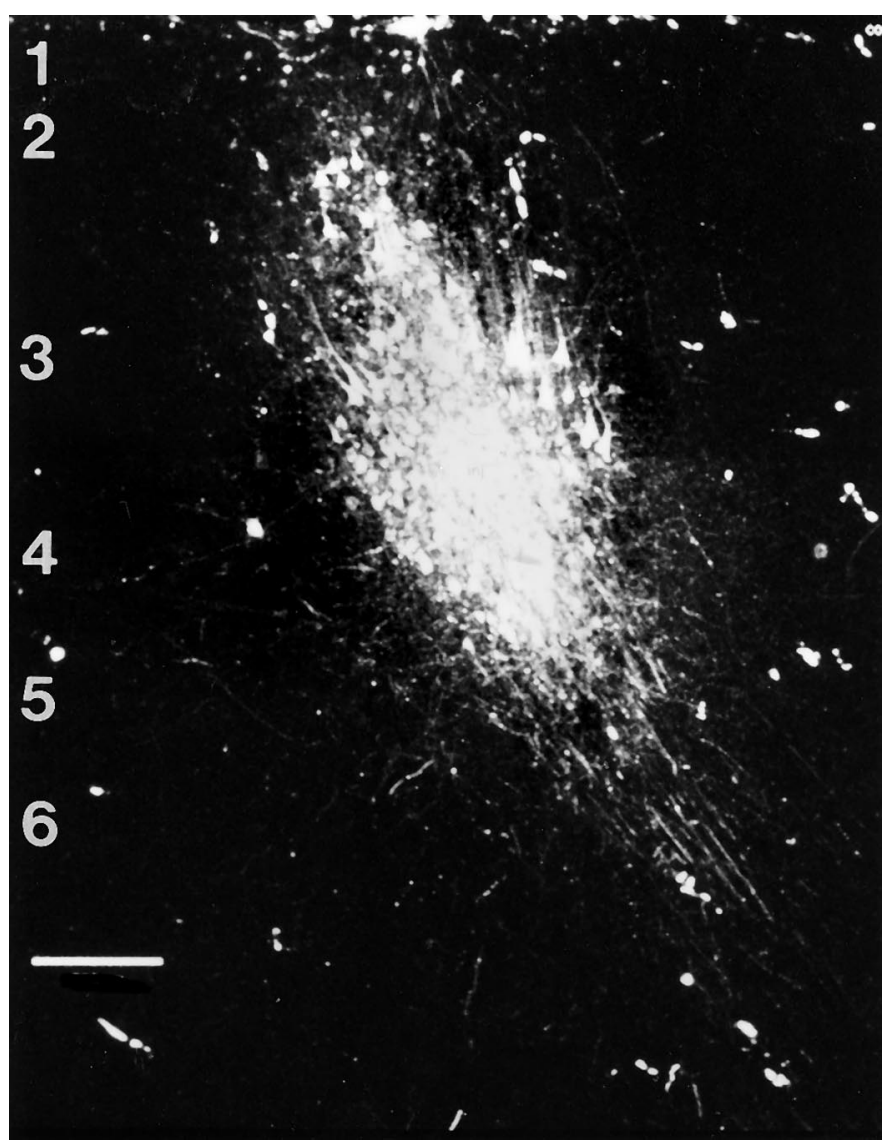

Figure 1. Scanning laser confocal image of a typical injection site $<500$ $\mu \mathrm{m}$ in diameter in area $3 \mathrm{~b}$. Labeled pyramidal cells adjacent to the injection site are seen. Horizontal fibers projecting through layers 3 and 5 of area $3 b$ are visible, as well as subcortical projection fibers. Scale bar, $250 \mu \mathrm{m}$.

interleaved imaging of both dyes. In the flattened maps, the border of area $3 \mathrm{~b}$ deep in the central sulcus is referred to as the "anterior border," and that with area 1 as the "posterior border." "Medial" means toward the midline of the hemisphere, and "lateral" means toward the lateral sulcus.

\section{RESULTS}

\section{Somatotopy of the hand/face border}

Neurons responding vigorously to light cutaneous stimulation of the contralateral hand or face under the anesthetic conditions of the experiments were located in area $3 b$, in the posterior bank of the central sulcus. Responses in area 1 under Nembutal anesthesia are much weaker (Powell and Mountcastle, 1959b). Only area $3 b$ will be described here. The representation of the thumb (D1), the representation of the lower jaw/neck region, and the representations of the lower and upper lips, muzzle, and dorsolateral aspect of the face were explored extensively, and common elements and variations in the representations are visible in Figures 3 and 4. D1 was represented in the most medial portion of the reconstructed maps. The exact somatotopy of the representation of D1 has been reported previously (Pons et al., 1987) and will be described only briefly.

Neurons responding to stimulation of the thenar eminence and of the proximal glabrous surface of D1 were located posteriorly in area $3 \mathrm{~b}$. The glabrous skin over the lateral aspect of the distal phalanx of D1 was represented anterior and lateral to the representation of the proximal glabrous parts of D1. 


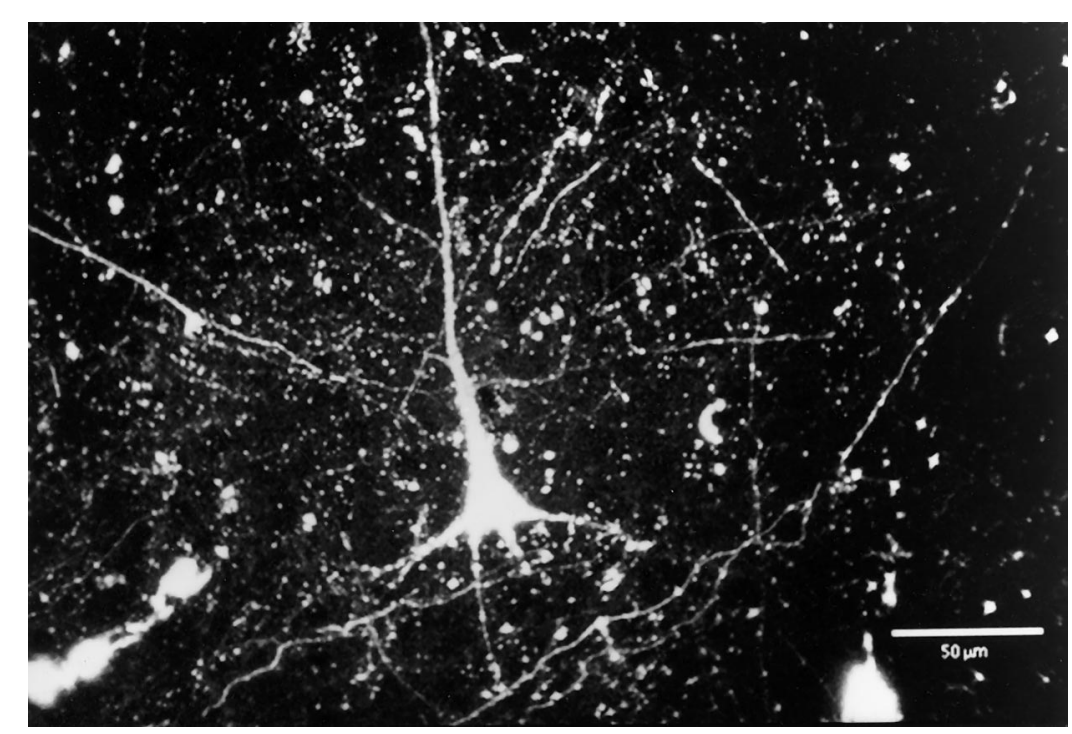

Figure 2. Scanning laser confocal image of a typical, retrogradely labeled pyramidal cell in layer 3 of area $3 b$. Numerous anterogradely labeled axons and terminals are also seen throughout the field.

Anterior to this was a small region of cortex in which neurons responded to stimulation of hairs on the dorsal aspect of D1. Anterior to this again and at the anterior border of area $3 b$, neurons responded to stimulation of the nail bed of D1. The glabrous skin covering the medial aspect of the distal phalanx of D1 was represented medial to the hairy skin and nail bed representations. The entire representation of $\mathrm{D} 1$ in area $3 \mathrm{~b}$ had a mediolateral extent of $\sim 2 \mathrm{~mm}$ and an anteroposterior extent of $\sim 6.5 \mathrm{~mm}$, the latter corresponding to the entire width of area $3 b$ at this level of the postcentral gyrus. The majority of the representation was devoted to the glabrous skin over the distal phalanx.

Lateral to the representation of D1 was the representation of the lower jaw and adjacent part of the neck. Although the internal organization of this representation varied from animal to animal, the overall representation was consistently located between the representation of D1 and that of the lips, muzzle, and dorsolateral aspect of the face (Figs. 3, 4). The lower jaw representation included the skin over the vertical ramus of the mandible anterior to the ear and extended anteriorly along the horizontal ramus of the mandible until replaced by the representation of the hairy part of the lower lip and adjacent muzzle and chin. Receptive fields in the lower jaw representation extended continuously onto the skin of the adjacent part of the neck, mainly its anterior and lateral portions, commonly extending to the midline of the neck and including the skin beneath the chin. The anterior border of the region was coincident with the area over which the texture and color of the hair changes from the soft, light downy hair of the jaw and neck to the wiry darker hair of the muzzle. We will refer to the region as a whole as the lower jaw/neck region. As recording sites moved anteriorly through the lower jaw/neck representation, receptive fields of neurons moved from posterior to anterior in the region (Figs. 3, 4). All receptive fields were located on both the jaw and neck, most extending under the jaw to the midline of the neck. No receptive fields located solely on the neck or solely on the lower jaw were observed. Receptive fields on lower jaw skin abutting the muzzle were located most anteriorly and often included the skin under the chin. The majority of the receptive fields of neurons in the lower jaw/neck representation were large in comparison with those of neurons in the representations of the lips and digits.

The representation of the lower jaw/neck lay between the representations of the first digit and the lips in all of the monkeys studied. The lower jaw/neck representation formed a band $\sim 1-1.5$ $\mathrm{mm}$ in mediolateral extent and of variable extent across the anteroposterior dimension of area $3 \mathrm{~b}$. In two of the cases, the posterior border of the representation was coincident with the posterior border of area $3 \mathrm{~b}$ (Fig. $3 A, B$ ). In the other two cases, the posterior border was separated from the posterior border of area $3 b$ by part of the representation of the dorsolateral face or by parts of the representations of D1 and of the hairy part of the lower lip (Fig. $4 A, B$ ). The anterior border of the representation was coincident with the anterior border of area $3 \mathrm{~b}$ in three of the cases (Figs. $3 A, 4 A, B$ ). In the remaining case, the anterior border was separated from the anterior border of area $3 \mathrm{~b}$ (Fig. $3 B$ ) by parts of the representations of D1 and of the hairy portion of the lower lip.

Lateral to the lower jaw/neck representation, the representations of the dorsolateral aspect of the face and of the upper and lower lips were located. The representation of the dorsolateral part of the face lay along the posterior border of area $3 \mathrm{~b}$. Anterior to this was the representation of the upper lip, and anterior to the upper lip representation was that of the lower lip. Details of the face representation in the macaque monkey have been published previously (Dreher et al., 1975; Manger et al., 1996).

\section{Anterograde and retrograde labeling in somatosensory cortex: intrinsic area $3 \mathrm{~b}$ connections and connections with adjacent fields}

Three of the cases received an injection of one tracer in the representation of D1 and of the other tracer in the representation of the hairy upper lip. The other three cases had one tracer injection in the representation of D1 and the second in that of the lower jaw/neck region, as defined above. For all cases, the microelectrode mapping of area $3 \mathrm{~b}$ preceding the injection of tracer enabled accurate placement of the tracer into area $3 \mathrm{~b}$ and into the representations of D1, of the lower jaw/neck region, or of the upper lip, and permitted subsequent plotting of labeled cells and fiber terminations in relation to the electrode tracks. Injections were all $\sim 500 \mu \mathrm{m}$ in both mediolateral and anteroposterior extent and confined to area 3b. All predominantly involved layers III and IV. Correspondingly, the majority of anterogradely labeled fibers and of retrogradely labeled cells were located in these layers, especially 

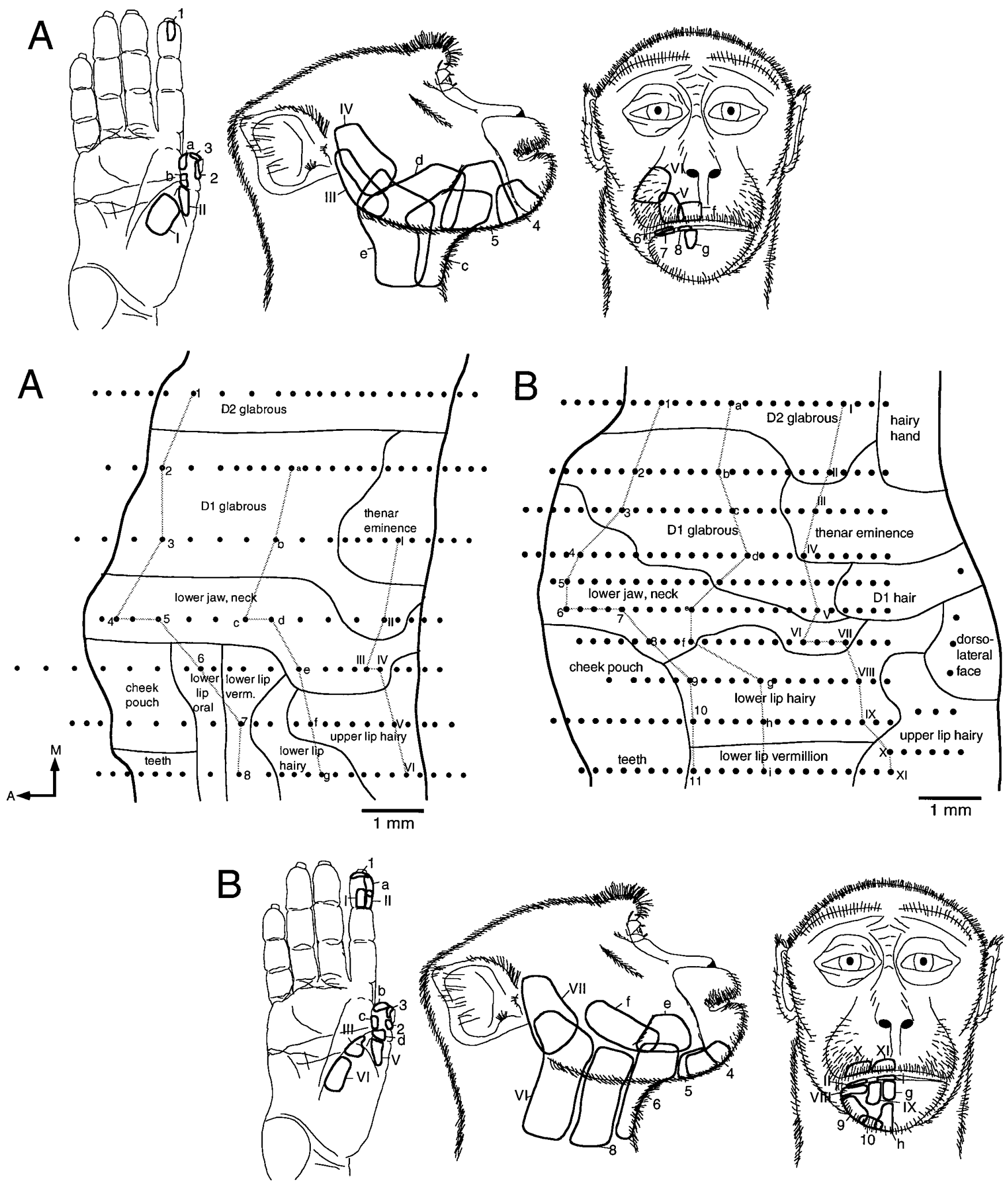

Figure 3. A, Flat map of area 3b, reconstructed from sagittal sections, showing the region in which the representations of the hand and face adjoin. A large representation of the thumb $(D 1)$ is found medial to a band of cortex containing neurons responsive to stimulation of the lower jaw/neck region. The receptive field examples drawn on the middle figure clearly delineate this region. The representation extends from the anterior to the posterior borders (dark lines) of area 3b. The remainder of the face is represented lateral to the lower jaw/neck region. Dots represent sites of electrode penetrations. Those penetrations from which receptive fields are illustrated are identified by letters or numbers and joined by gray lines. A, Anterior; $M$, medial. $B$, Reconstructed flat map of the lower jaw/neck representation and adjacent representations in area $3 b$. The same conventions described in $A$ are used. In this case, the representation extends to the anterior border of area $3 \mathrm{~b}$, but posteriorly the representations of D1 and of the hairy lower lip intervene. Medial and lateral to the lower jaw/neck representation are the representations of D1 and of the rest of the face, respectively. 

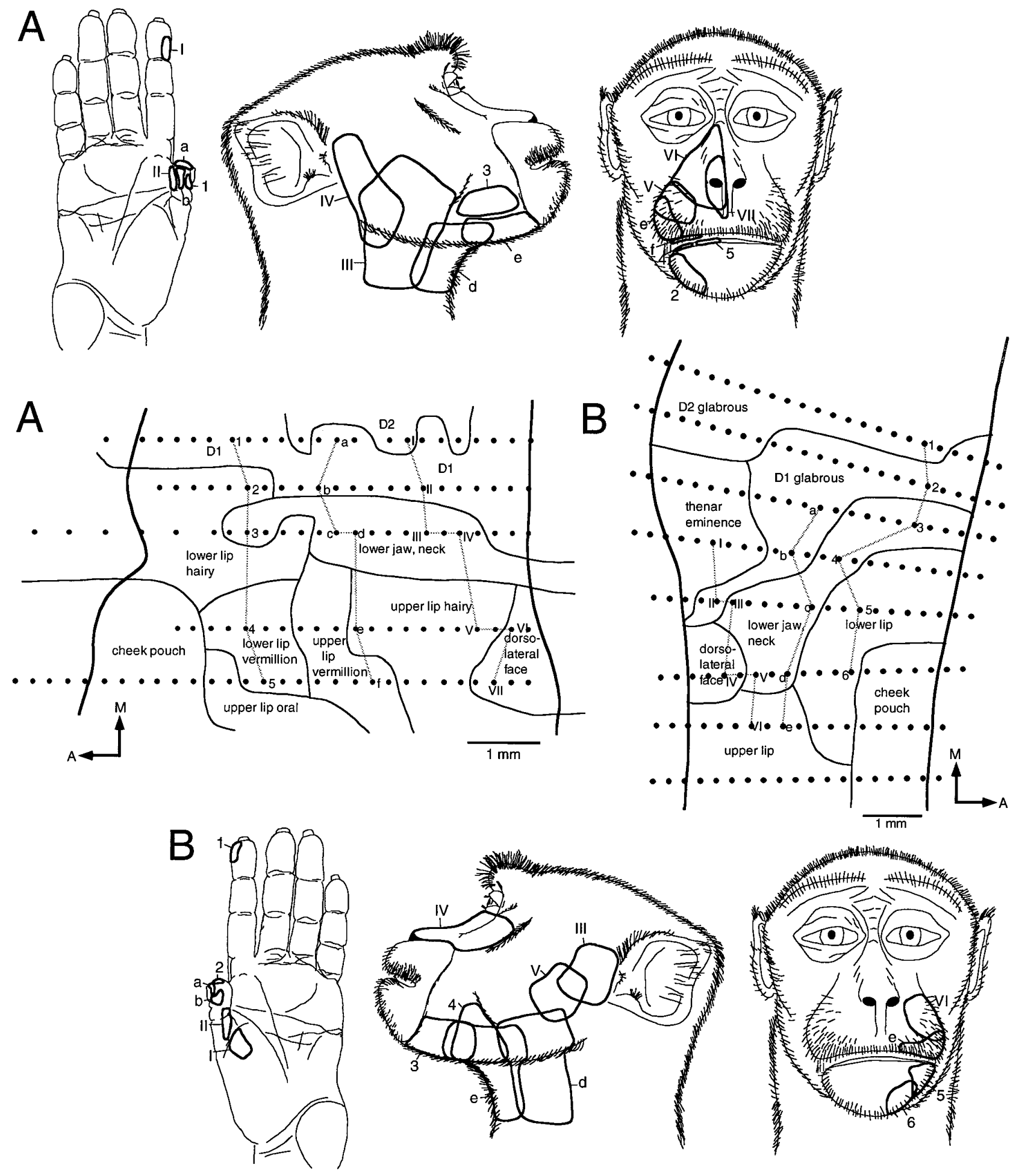

Figure 4. A, Reconstructed flat map of the lower jaw/neck and adjacent representations in area 3b. The same conventions described in Figure 3 are used. In this case, the representation of the lower jaw/neck does not form a complete anteroposterior band across area $3 \mathrm{~b}$. The posterior portion of the representation extends to the posterior border of area $3 \mathrm{~b}$, but anteriorly the representation of the hairy part of the lower lip intervenes. Medial and lateral to this representation are the representations of $\mathrm{D} 1$ and of the rest of the face, respectively. $B$, Reconstructed flat map of the lower jaw/neck representation and adjacent representations in area $3 \mathrm{~b}$. The same conventions described in $A$ are used. In this case, the anterior border of the representation extends to the anterior border of area $3 \mathrm{~b}$, but the posterior border is separated by the representation of the dorsolateral face. The lower jaw/neck representation is again bordered by the representations of D1 and of other facial structures, respectively. 
in layer III, but significant numbers of labeled cells and fibers were found in layers II, V, and VI as well.

In the three cases in which the injections of tracer were made into the representations of D1 and of the upper lip, the results were highly consistent (Figs. 5-7). Emanating from each injection was an asymmetric pattern of cell and fiber labeling in area $3 \mathrm{~b}$. Injections of tracer in the representation of the hairy upper lip led to a majority of labeled cells and terminal ramifications lateral to the injection site (i.e., in the face representation) and extending for at least $3 \mathrm{~mm}$ mediolaterally (shown in full in Fig. 5). By contrast, medial to the upper lip injections, labeled cells and terminal ramifications extended for a distance of no more than 1 $\mathrm{mm}$, at which point the labeled cell bodies and terminations ended abruptly. The sharp medial boundary of labeled cells and fiber terminations corresponded to the lateral boundary of the lower jaw/neck representation, as determined from the mapping before injection.

For injections made in the representation of D1 in these cases, the asymmetry in the labeling pattern was reversed, with the majority of labeled cell bodies and fiber ramifications being found medial to the injection site (i.e., in the representation of the digits), the labeled fibers in particular extending in layer III for distances up to $4 \mathrm{~mm}$. This was 1-2 $\mathrm{mm}$ beyond the medial limit of retrogradely labeled cell bodies. Lateral to the injection site, the labeled cells and terminals ended abruptly in a manner comparable with that seen medial to injections in the lip representation. This sharp boundary did not occur at the lateral border of the D1 representation but at the lateral border of the lower jaw/neck representation, ending abruptly at its border with the representation of the lips.

In all three cases there was only very slight overlap $(\sim 200 \mu \mathrm{m}$ mediolaterally) of cells and fiber terminations labeled with one or other of the two dyes (Figs. 5-7), and no double-labeled cells or fibers were observed. The short region of overlap invariably occurred at the lateral boundary of the representation of the lower jaw/neck region in area $3 \mathrm{~b}$.

Of the somatosensory cortical areas adjacent to area $3 b$, only areas $3 \mathrm{a}$ and 1 were examined in detail. In both areas, foci of cells and fiber ramifications labeled by each dye were clearly separated from one another, and there was only very slight overlap, if any, in their distributions. In accord with previous reports of the connections of the different somatosensory areas, more dense cell and fiber labeling was found in area 1 with sparser labeling in area $3 \mathrm{a}$. Also as reported previously, the pattern of cell and fiber labeling in all three areas was patchy (Jones et al., 1978; Shanks et al., 1985; Krubitzer and Kaas, 1990; Burton and Fabri, 1995).

In three cases, the paired injections were made in the physiologically determined representations of D1 and of the lower jaw/neck region of area 3b. Two are illustrated in Figures 8 and 9. As seen with the previous cases, the pattern of anterogradely and retrogradely transported label in the granular and supragranular layers of area $3 b$ was asymmetrically distributed around each injection site. For both injections, the labeling extended further medially than laterally in the D1 and lower jaw/neck representations and formed a sharp border at the upper lip representation. There was an extensive amount of overlap in the distributions of cells and fiber ramifications labeled with each dye. The extent of overlap was not as great for the retrogradely labeled cells. There was, nevertheless, a lack of double-labeled cells, only two being found in area $3 \mathrm{~b}$ and none in areas 1 or $3 \mathrm{a}$.

For the injection in the D1 representation in these cases, the transported label extended for $\sim 4 \mathrm{~mm}$ medial to the injection site in area $3 b$ (full medial extent not shown). As seen with the cases described above, the cell and fiber labeling ensuing from the D1 injection overlapped the representation of the lower jaw/neck region and formed a sharp boundary with the lip representation at the lateral border of the lower jaw/neck representation, $2.5 \mathrm{~mm}$ lateral to the injection site. The lateral extent of the cell and fiber labeling ensuing from the injection in the lower jaw/neck representation also terminated at the lateral border of this representation, $1 \mathrm{~mm}$ lateral to the injection site, and did not extend into the representations of the lips, muzzle, or dorsolateral part of the face. Medially, however, the labeling emanating from this injection extended for $2 \mathrm{~mm}$ into the D1 representation, overlapping extensively with the cells and fibers labeled by the other dye. In area 1 there was a similar amount of overlap of the transported label, especially the anterograde label. The transported label in area 1 did not extend mediolaterally over a distance greater than that in area $3 b$. The distribution of the transported label in areas $3 \mathrm{a}, 3 \mathrm{~b}$, and 1 was patchy.

\section{DISCUSSION}

\section{Somatotopy at the hand/face border representation}

In previous studies of macaque monkeys, Woolsey et al. (1942) and Nelson et al. (1980) demonstrated that lateral to the D1 representation, a band of cortex responds to stimulation of the region defined in the present study as lower jaw/neck and confirmed as separating the representations of D1 and those of the lips or muzzle.

Woolsey et al. (1942), Dreher et al. (1975), Bioulac and Lamarre (1979), and Nelson et al. (1980) also obtained responses to stimulation of receptive fields on the occiput, neck, and side of the head in cortex medial to the representation of the hand. Woolsey (1958, his Fig. 22), in an effort to preserve the idea of continuous somatotopy, made a hypothetical union of the lateral representation of the lower jaw and neck and of the medial representation of the occiput, neck, and scalp via a thin cortical zone located posterior to the hand representation. The present study found no indications of extensions of the lower jaw/neck representation or of the occiput, posterior part of the neck and scalp representation into the region posterior to the hand representation in area $3 \mathrm{~b}$. Thus, areas of skin innervated by anterior (lower jaw and neck) and posterior (scalp and occiput) primary rami of the upper cervical nerves have discontinuous representations in area $3 b$.

\section{Intrinsic connections of hand, lower jaw/neck, and face representations}

The experiments demonstrated that the muzzle representation in area $3 \mathrm{~b}$ lacks intracortical connections with the representations of the hand or of the lower jaw and neck; however, the representations of the lower jaw and neck and of the digits are strongly interconnected. The implication is that cortex representing cutaneous areas innervated by anterior primary rami of cervical spinal nerves is continuously connected, but the continuity ends abruptly at the border with the representation of areas innervated solely by the mandibular nerve. In primary motor cortex, the hand and face representations, as defined by intracortical microstimulation (Huntley and Jones, 1991), show a similar delimiting border; horizontal connections emanating from a representation of thumb movements, although spreading extensively throughout the upper limb representation, do 


\section{Anterograde and Retrograde label}

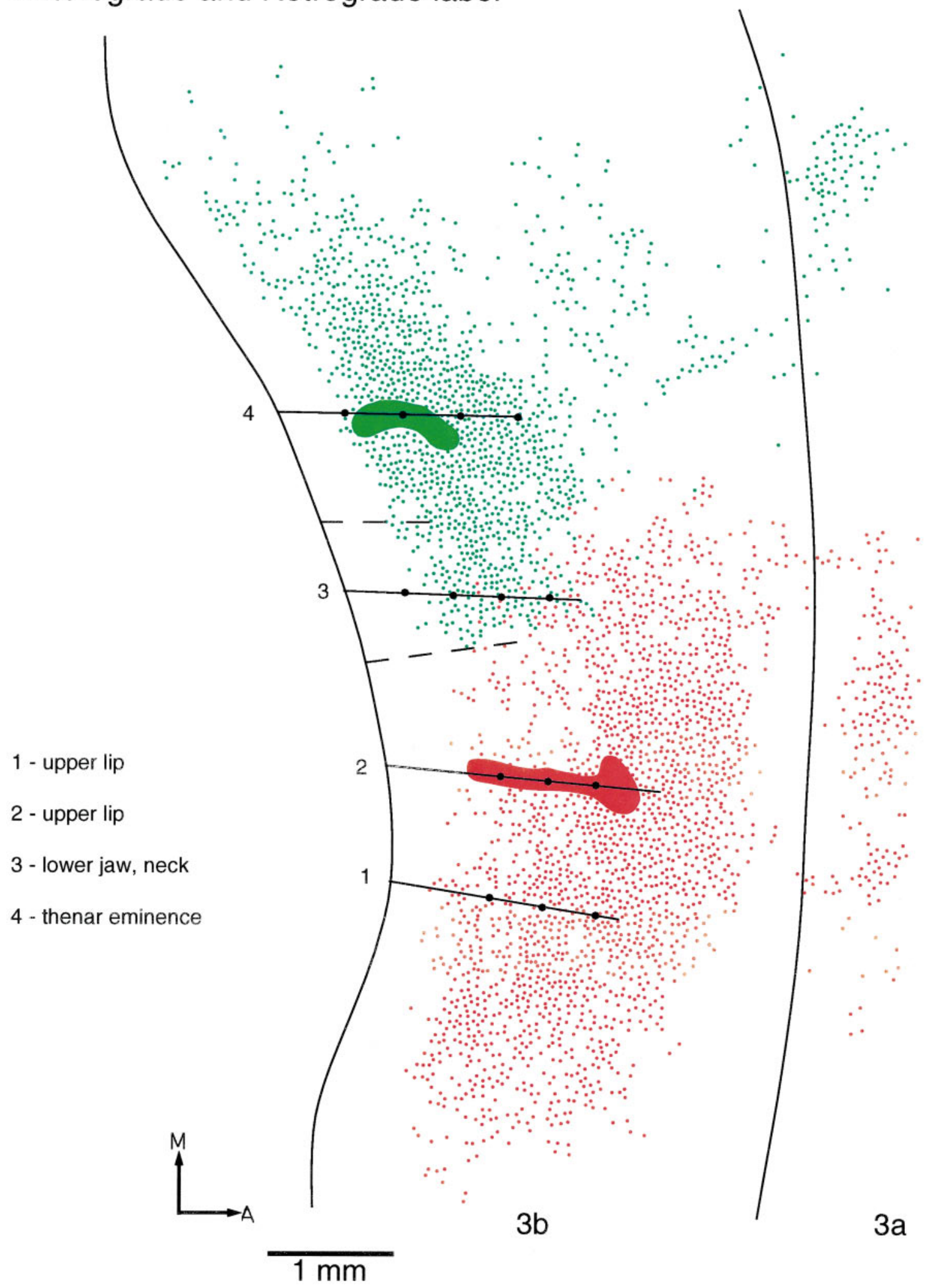

Figure 5. Reconstructed flat map combining the patterns of anterograde and retrograde labeling resulting from two injections in area $3 \mathrm{~b}$. Fluorescein-dextran (green) was injected in the representation of the thenar eminence, and FluoroRuby (red) was injected in the representation of the upper lip. For retrograde labeling, each dot represents one cell. For anterograde labeling, each dot represents a cluster of large boutons (usually 3-5). Recording sites (dots) and electrode penetrations (lines) are indicated. Broken lines indicate borders of the lower jaw/neck representation. Intrinsic connections spread widely within the hand and the lower jaw/neck representations and within the rest of the face representation, but there is little overlap between the two. In this figure, the full mediolateral extent of labeling in area $3 \mathrm{~b}$ is shown. In subsequent figures, only labeling in the immediate vicinity of the hand/face border is shown. $A$, Anterior; $M$, medial. 


\section{Anterograde label}

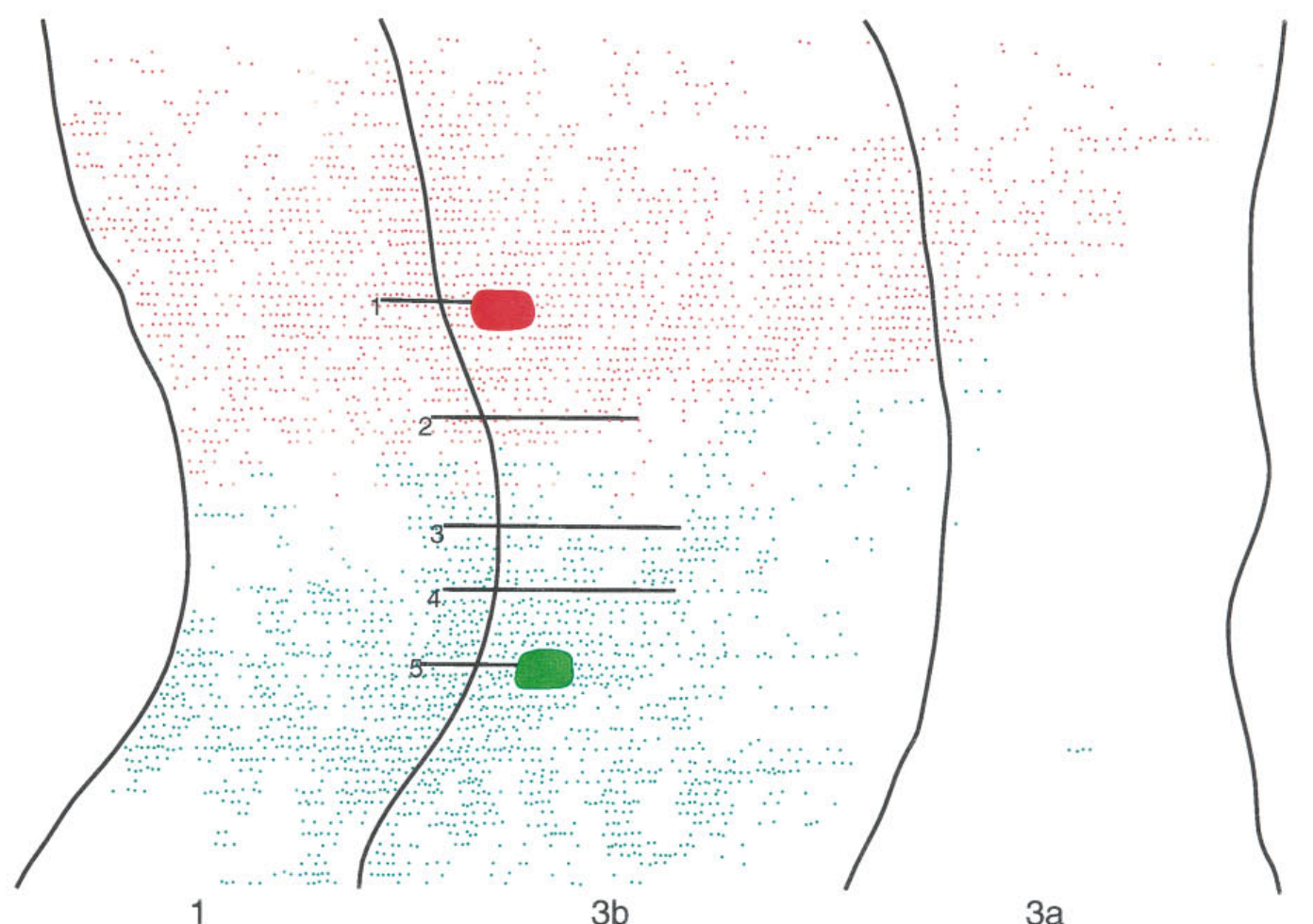

\section{Retrograde label}

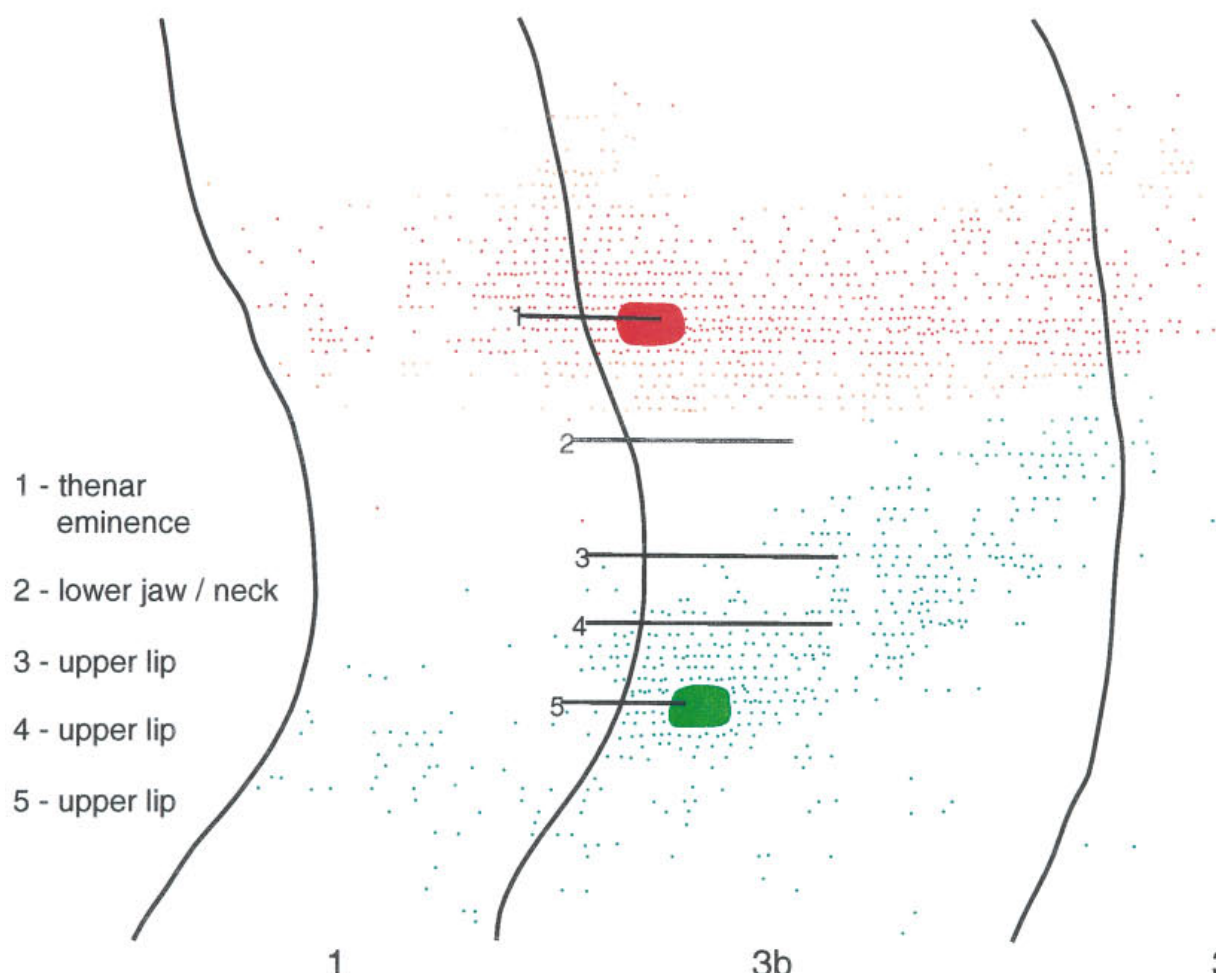

1
$3 b$
$3 a$

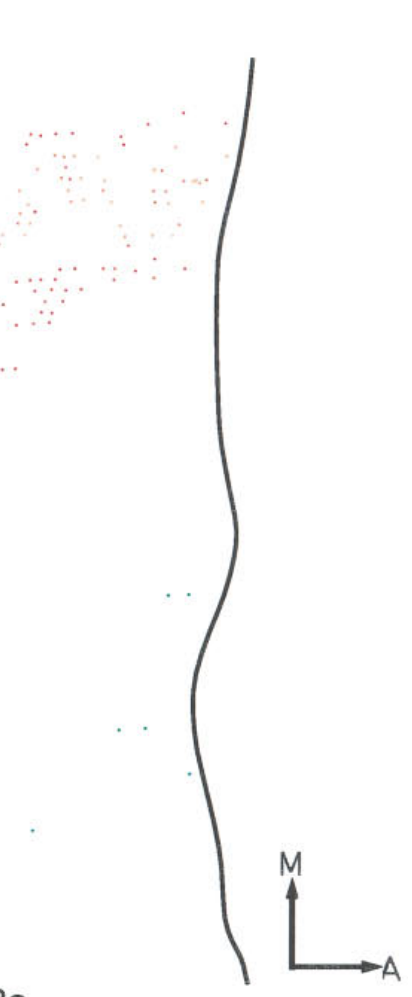

$1 \mathrm{~mm}$

Figure 6. Reconstructed flat maps showing individually the patterns of anterograde and retrograde labeling resulting from two injections in area $3 \mathrm{~b}$. FluoroRuby was injected in the representation of the thenar eminence, and Fluorescein-dextran was injected in the representation of the upper lip. Although extensively distributed, anterograde and retrograde labeling from each injection site shows little or no overlap and forms a distinct boundary at the region that corresponds to the lateral border of the representation of the lower jaw and neck. The injection in the representation of the hand results in denser labeling in area $3 \mathrm{a}$ than does the injection made in the representation of the upper lip. Both injections demonstrate equally strong connections with area 1. $A$, Anterior; $M$, medial. 


\section{Anterograde label}

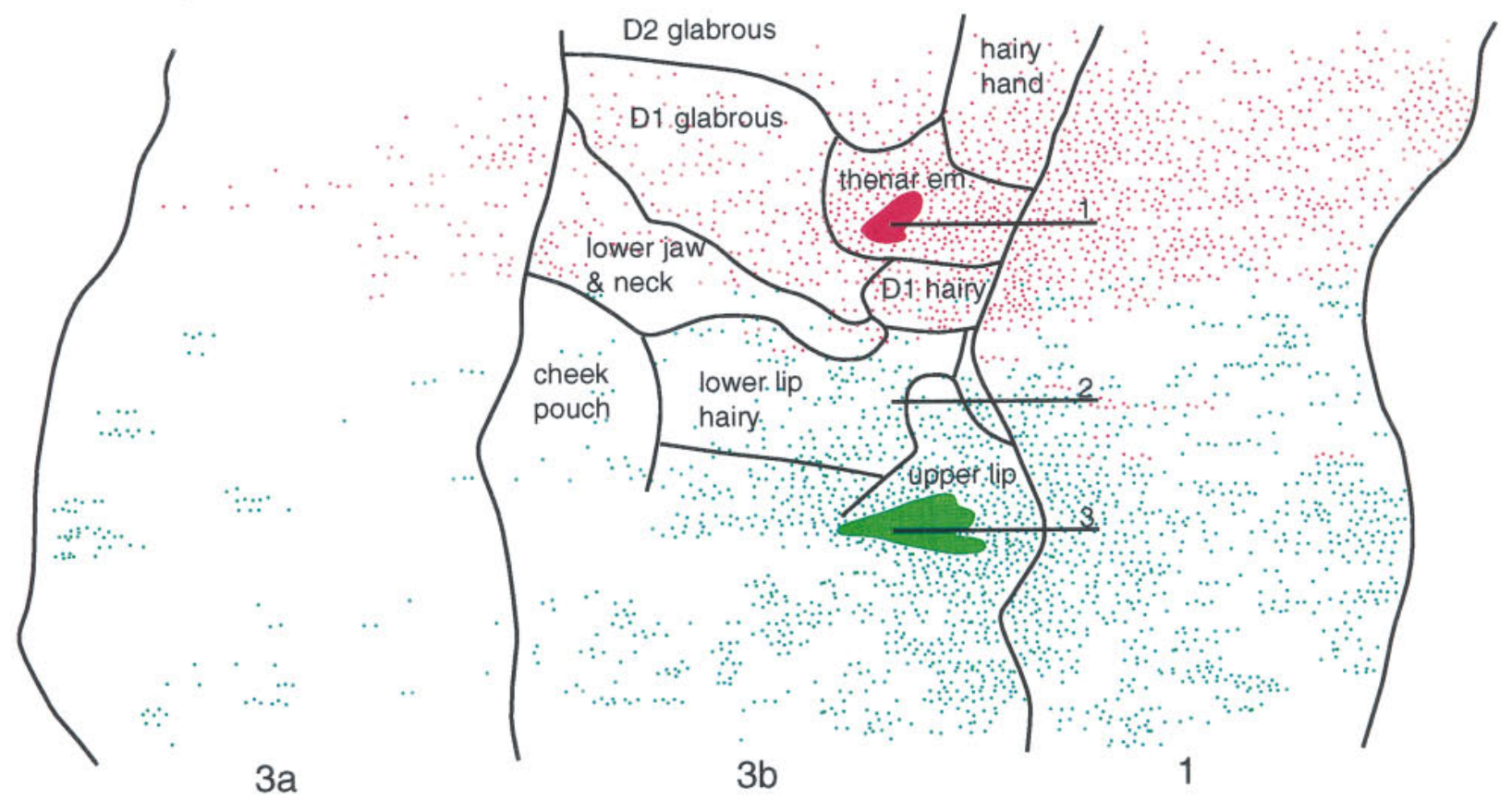

\section{Retrograde label}

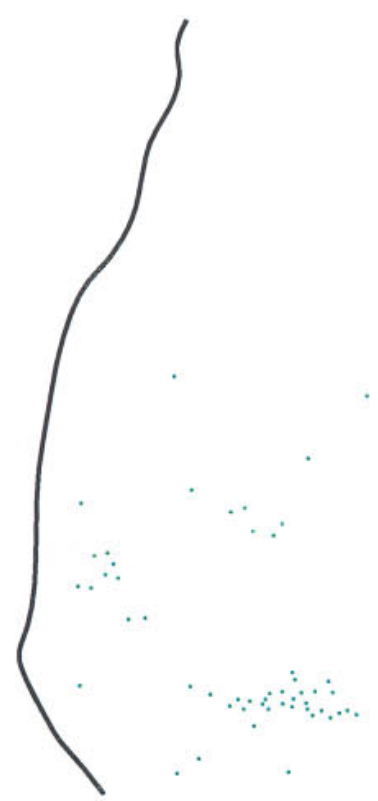

$3 a$
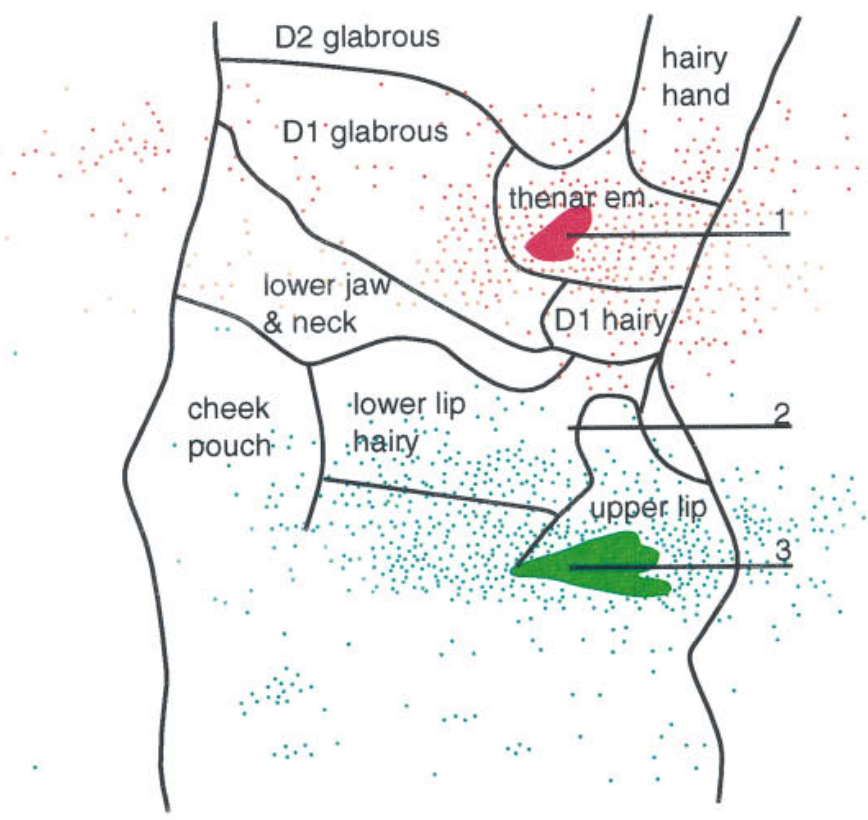

$3 b$

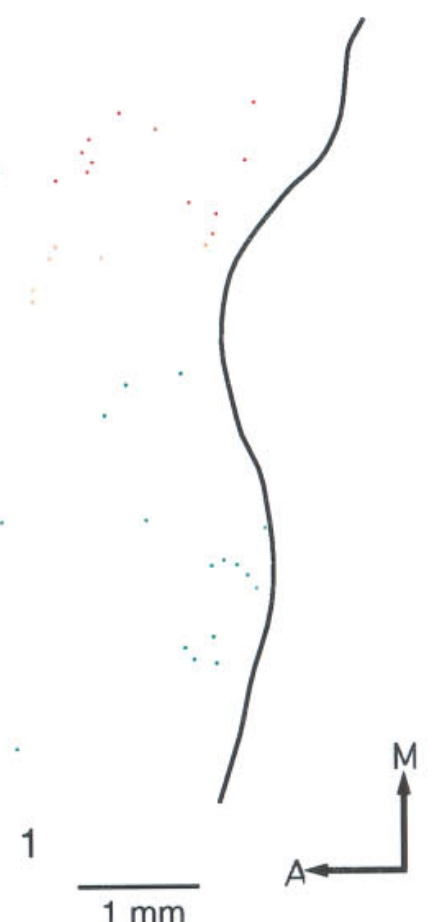

\section{1 - thenar eminence}

$1 \mathrm{~mm}$

\section{2 - dorsolateral face, trigeminal}

\section{3 - upper lip}

Figure 7. Reconstructed flat maps of the patterns of anterograde and retrograde labeling resulting from two injections in area $3 \mathrm{~b}$. FluoroRuby was injected in the representation of the thenar eminence, and Fluorescein-dextran was injected in the representation of the upper lip. Selected recording tracks are shown. The partial map of the representation was derived from other penetrations. The injection made in the representation of the upper lip shows strong anterograde labeling extending throughout the representation of the dorsolateral face, whereas that made in the representation of the thenar eminence shows similarly strong labeling extending through the hand and lower jaw/neck representations. There is a clear boundary, however, at the junction of the representation of the lower jaw and neck and the representation of the lip, across which the connections do not overlap. $A$, Anterior; $M$, medial. 


\section{Anterograde label}

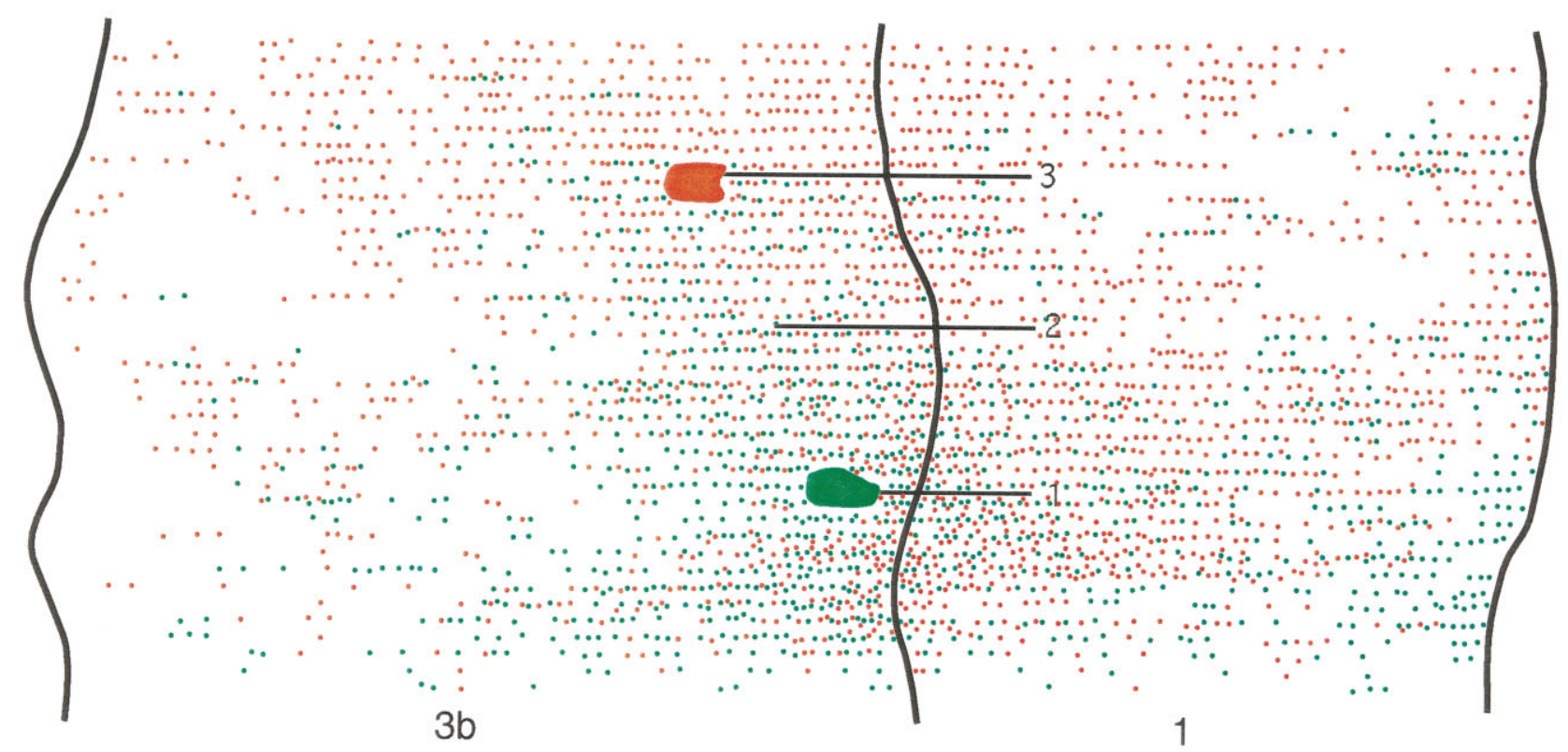

\section{Retrograde label}
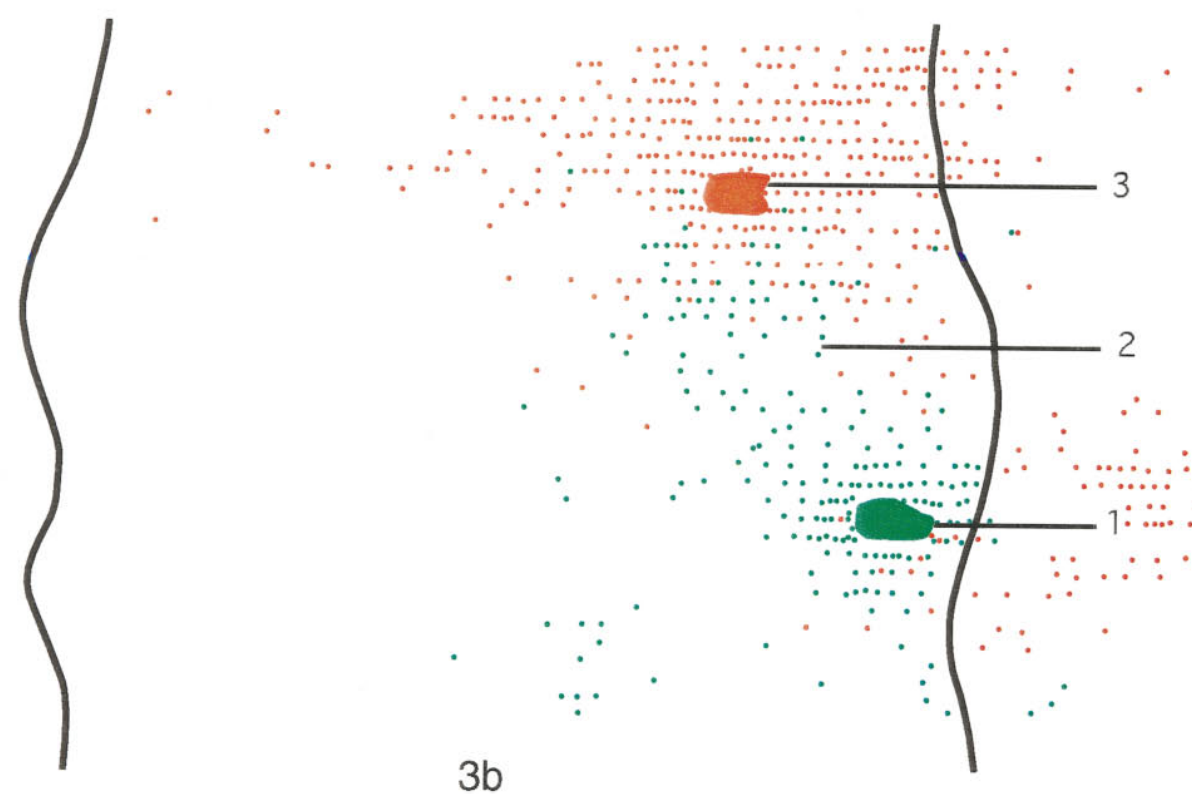

$3 b$

1

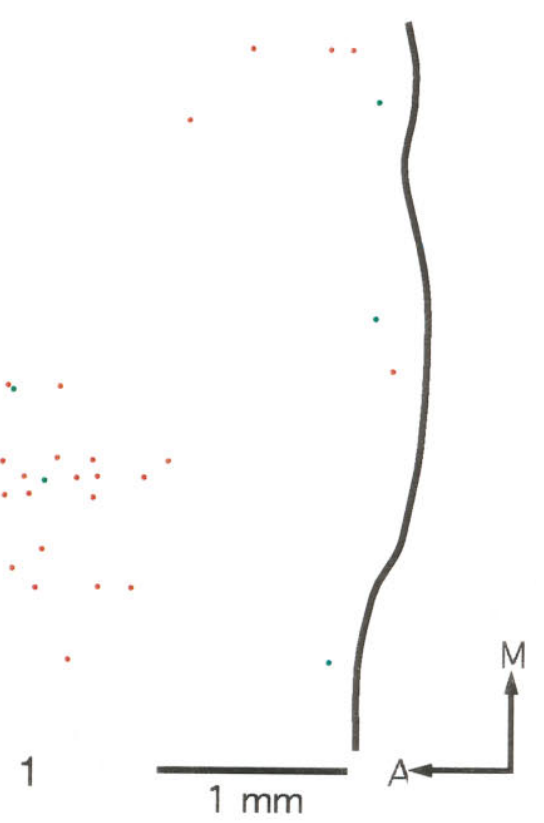

1 - angle of jaw, cheek adjacent to ear

2 - angle of jaw

3 - tip of thumb

Figure 8. Reconstructed flat maps of the patterns of anterograde and retrograde labeling resulting from two injections in area $3 \mathrm{~b}$. FluoroRuby was injected in the representation of glabrous D1, and Fluorescein-dextran was injected in the representation of the lower jaw and neck. This and the following case (Fig. 9) differ from the previous three (Figs. 5-7) in that the labeling patterns overlap extensively in area $3 \mathrm{~b}$ as well as in area 1 . Despite the extensive overlap in connectional patterns, very few cells were retrogradely labeled with both tracers. $A$, Anterior; $M$, medial. 


\section{Anterograde label}

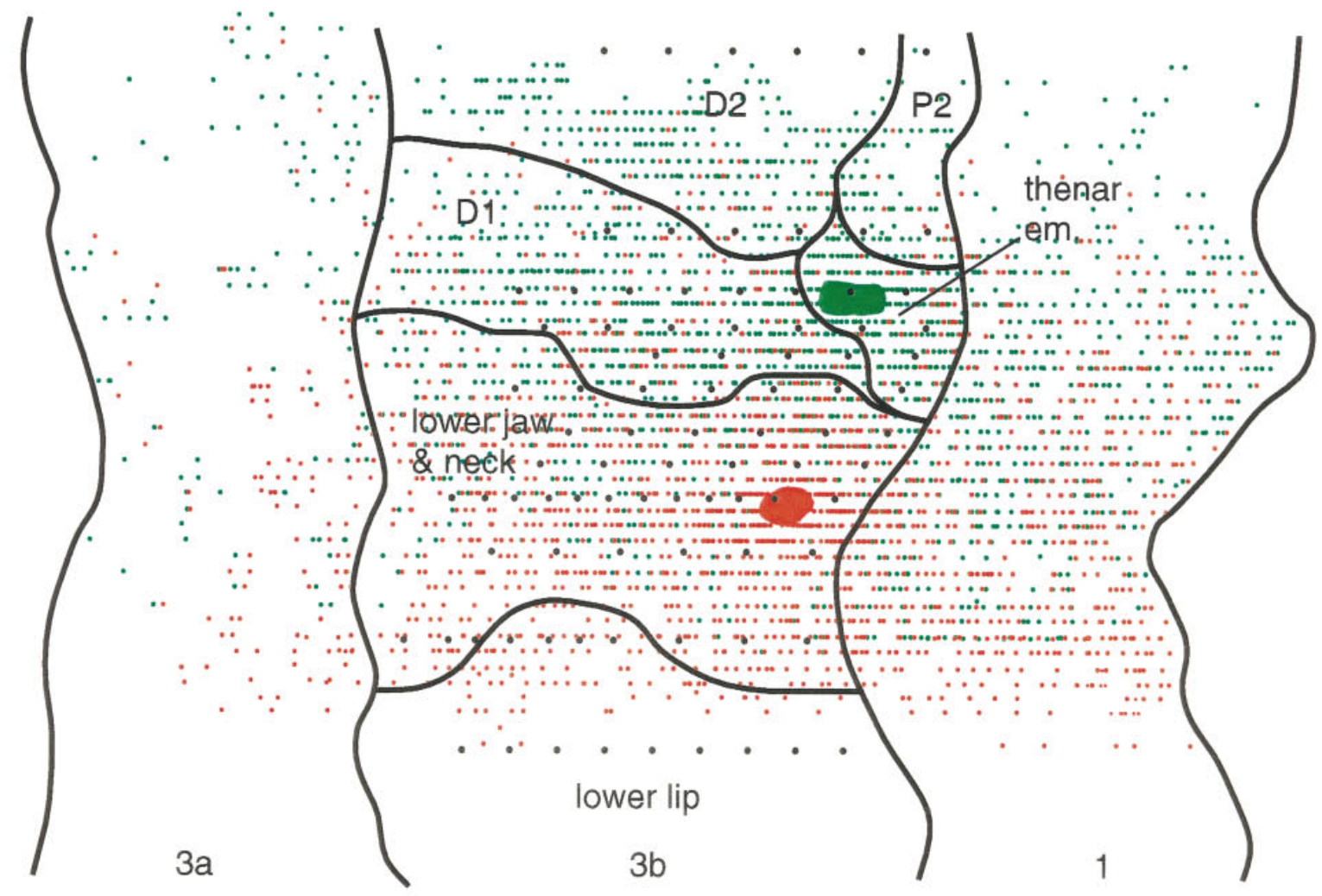

Retrograde label

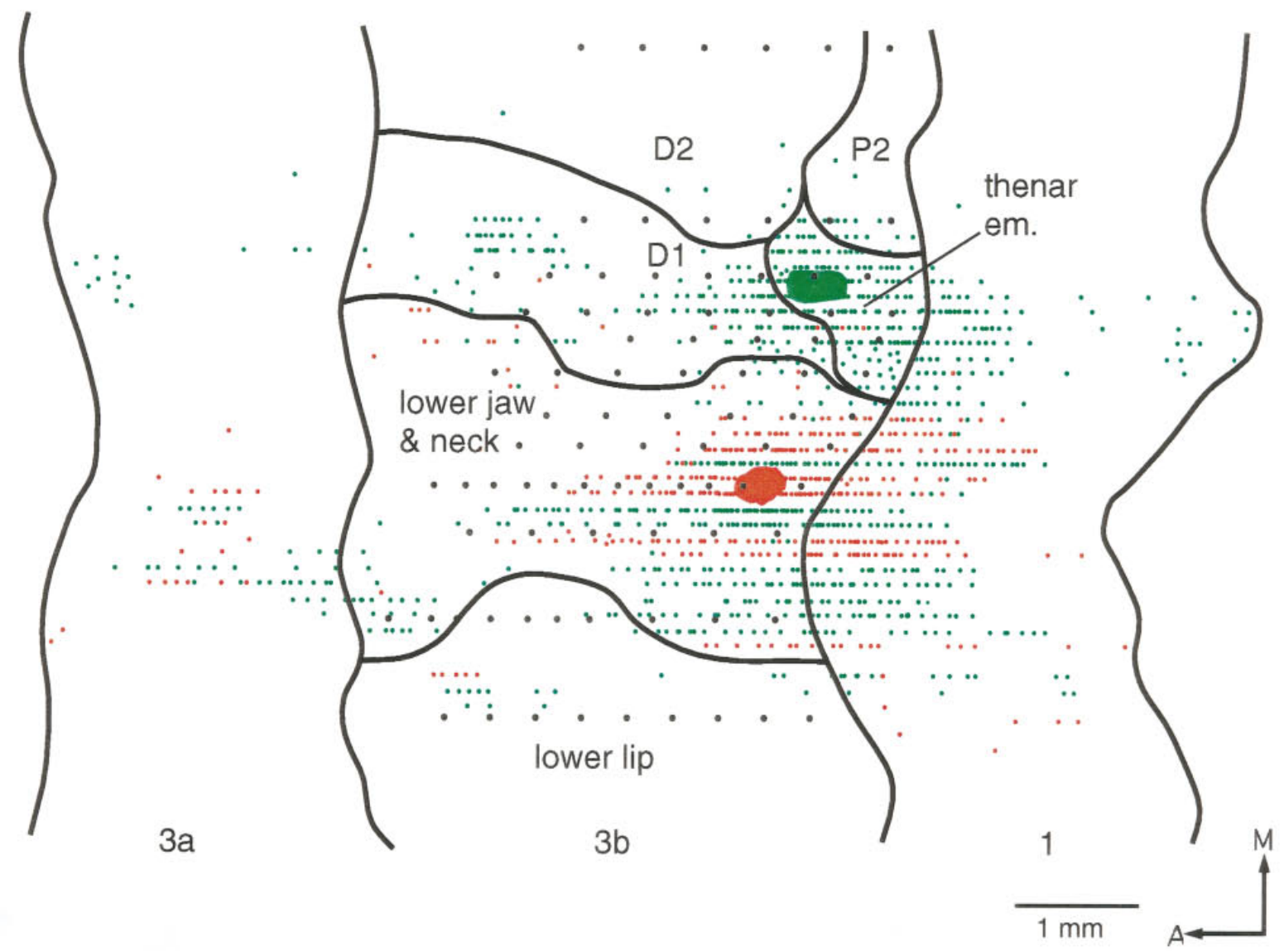


not cross into the face representation. The border between trigeminal and cervical representations thus appears to be a "protected" one. This contrasts with the extensive spread of connections within the representations of the digits in area $3 \mathrm{~b}$ (Jones and Powell, 1969; Burton and Fabri, 1995; present study). These extensive connections may help account for reorganization of the hand representation under usedependent conditions or after intracortical microstimulation (Recanzone et al., 1992a,b). In accounting for activitydependent expansions of the upper limb representation into that of the face, however, it now becomes necessary to consider whether these cross the protected border or are confined within the representation of the cervically innervated, lower jaw/neck region. Preexisting corticocortical connections clearly cannot account for expansion of the representation of the rest of the face into that of the hand.

The anterior primary ramus of the second cervical nerve innervates the lower jaw/neck region as defined in the present study; the jaw component of this skin field is overlapped extensively by the distribution of the mandibular nerve (Sherrington, 1939). The mandibular distribution extends from the lips and muzzle to the rami of the mandible and angle of the jaw but not onto the neck. In the present study, receptive fields of neurons in the lower jaw/neck representation usually extended over both lower jaw and neck, i.e., into the territory of overlap, whereas those of neurons in the muzzle and lip representations never extended onto the lower jaw/neck region. Therefore, central neurons receiving inputs from the lower jaw region via the mandibular nerve apparently do not have detectable inputs from mandibular fibers innervating the lips and muzzle. The pattern of intracortical connections tends to reflect the peripheral innervation pattern; there is extensive overlap of the connections in the lower jaw/neck and in the D1 representations but little across the border between the lower jaw/neck and the lip and muzzle representations.

Whether overlap of cervical and mandibular nerve inputs occurs at lower levels of the somatosensory pathway, particularly the thalamus, is unclear. The lower jaw/neck region is represented in VPL (Jones and Friedman, 1982; Jones et al., 1982) which receives only dorsal column-lemniscal and spinal inputs; these do not overlap into the ventral posterior medial nucleus (VPM) (Tracey et al., 1980; Jones et al., 1982; Asanuma et al., 1983). Neurons responding to stimulation of the lower jaw and neck region have never been reported in VPM (Jones et al., 1986a; Rausell and Jones, 1991a); VPM receives only trigeminal inputs which do not overlap into VPL (Jones et al., 1986b; Rausell and Jones, 1991b). Studies of somatotopy in the dorsal column and principal trigeminal nuclei of monkeys (Kerr et al., 1968; Ferrington et al., 1988; Culbertson and Brushart, 1989; Florence et al., 1989) have not reported whether lower jaw and neck representations are found in both nuclei. There is, however, extensive overlap of upper cervical and trigeminal inputs in the caudal spinal trigeminal nucleus (Kerr, 1972). The outputs of the caudal nucleus are relayed to area $3 \mathrm{~b}$ by small-celled populations in and around VPM (Rausell and Jones, 1991b).

\section{Implications for cortical plasticity}

After long-term C2-T4 dorsal rhizotomies in monkeys, Pons et al. (1991) described expansion of the face representation over a region of cortex that presumably had been once occupied by the upper limb representation. The extent of this expansion (10-14 $\mathrm{mm}$ ) exceeds the cortical distance limit determined by divergence of thalamocortical afferents (Garraghty and Sur, 1990; Rausell and Jones, 1995). Significantly, the expanded part of the representation was restricted to that of the lower jaw region, minus the neck. Pons et al. (1991) proposed that a cascade of expansion ascending through subcortical somatic sensory nuclei and determined by preexisting divergence at all levels may be sufficient to account for the large change in the cortex (Garraghty and Kaas, 1991; Kaas, 1991; Petit and Schwark, 1993; Florence and Kaas, 1995). In these animals, however, most of the relay cells of the cuneate nucleus and of the medial half of the VPL nucleus were obliterated by transneuronal degeneration (Rausell et al., 1992). Hence, expansion of the lower jaw and face representation on the basis of divergence would have had to occur at trigeminal relay centers within the brainstem and/or thalamus and/or within the cortex itself.

The extent of normal thalamocortical divergence from VPM in relation to the hand and face representations has not been determined, but on the basis of the results of Rausell and Jones (1995), it is unlikely to be sufficiently extensive to support on its own a 10-14 mm expansion of the lower jaw representation. When coupled with the extensive spread of intracortical connections from the lower jaw/neck representation into that of the hand, however, expansions beyond the range of thalamocortical divergence become feasible. Expansion of representations of parts of the head located medial to the hand representation, as advocated by Lund et al. (1994), seems less likely in view of the lack of evidence for representations of the lower jaw skin in these parts of area 3b (Nelson et al., 1980; Manger et al., 1996; present study). It should be noted, however, that in the areas of skin represented medially, the distributions of posterior primary rami of upper cervical nerves and of the ophthalmic nerve overlap in a manner akin to that of anterior rami and the mandibular nerve in the lower jaw region (Sherrington, 1939). The horizontal connections of this part of the representation should be explored. Potentially, a lower jaw representation located posteriorly in area 1 could expand into the hand representation on the basis of preexisting trigeminal thalamocortical connections, but this has not been demonstrated. Contributing to the divergence of mandibular nerve-mediated thalamocortical input in the chronically deafferented monkeys may have been the diff usely projecting, calbindin immunoreactive cells of the VPM matrix (Rausell and Jones, 1991a) which are selectively innervated by afferents ascending from the spinal trigeminal nucleus (Rausell and Jones, 1991b) and which showed immunoreactive changes indicative of heightened activity in these monkeys (Rausell et al., 1992).

The present results suggest that preexisting horizontal, intracortical connections could account for expansion of the lower jaw representation into that of the hand, provided that input (pre-

Figure 9. Reconstructed flat maps of the patterns of anterograde and retrograde labeling resulting from two injections in area $3 \mathrm{~b}$. Fluorescein-dextran ( green) was injected in the representation of the thenar eminence, and FluoroRuby (red) was injected in the representation of the lower jaw/neck. Selected recording tracks are shown. The partial map of the representation was derived from other penetrations. As shown in Figure 8, there is extensive overlap of the labeled cells and fibers emanating from the two injection sites. $A$, Anterior; $M$, medial. 
sumably carried via the mandibular nerve) reaches the lower jaw representation. The extent of the horizontal connections, at least $3 \mathrm{~mm}$, is insufficient, however, to account for a 10-14 mm expansion. Such an extensive expansion may depend on a number of additional mechanisms. Divergence at subcortical levels is obviously one, and sprouting of the horizontal connections (DarianSmith and Gilbert, 1994) is potentially another; topographically mismatched inputs to area $3 \mathrm{~b}$ from mandibular nerve-mediated representations in other somatosensory cortical fields (Robinson and Burton, 1980; Krubitzer and Kaas, 1990; Krubitzer et al., 1993) may also contribute.

The present results show that preexisting horizontal connections cannot support expansion of any part of the lower face representation other than that of the lower jaw into the hand representation, because they do not transgress a border set by the anterior limit of the $\mathrm{C} 2$ innervation territory. This may be a key factor in restricting expansion of the representation to that of the lower jaw in monkeys subjected to chronic deafferentation of the upper limb.

\section{REFERENCES}

Asanuma C, Thach WT, Jones EG (1983) Distribution of cerebellar terminations and their relation to other afferent terminations in the ventral lateral thalamic region of the monkey. Brain Res 286:237-265.

Bioulac B, Lamarre Y (1979) Activity of postcentral cortical neurons of the monkey during conditioned movements of a deafferented limb. Brain Res 172:427-437.

Burton H, Fabri M (1995) Ipsilateral intracortical connections of physiologically defined cutaneous representations in areas $3 \mathrm{~b}$ and 1 of macaque monkeys: projections in the vicinity of the central sulcus. J Comp Neurol 355:508-538.

Culbertson JL, Brushart TM (1989) Somatotopy of digital nerve projections to the cuneate nucleus in the monkey. Somatosens Res 6:319-330.

Darian-Smith C, Gilbert CD (1994) Axonal sprouting accompanies functional reorganization in adult cat striate cortex. Nature 368:737-740.

Dreher DA, Loe PR, Metz CB, Whitsel BL (1975) Representation of the head and face in the postcentral gyrus of the macaque. J Neurophysiol 38:714-734.

Ferrington DG, Downie JW, Willis WD (1988) Primate nucleus gracilis neurons: responses to innocuous and noxious stimuli. J Neurophysiol 59:886-905.

Florence SL, Kaas JH (1995) Large-scale reorganization at multiple levels of the somatosensory pathway follows therapeutic amputation of the hand in monkeys. J Neurosci 15:8083-8095.

Florence SL, Wall JT, Kaas JH (1989) Somatotopic organization of inputs from the hand to the spinal gray and cuneate nucleus of monkeys with observations on the cuneate nucleus of humans. J Comp Neurol 286:48-70.

Florence SL, Garraghty PE, Wall JT, Kaas JH (1994) Sensory afferent projections and area $3 \mathrm{~b}$ somatotopy following median nerve cut and repair in macaque monkeys. Cereb Cortex 4:391-407.

Garraghty PE, Kaas JH (1991) Large scale functional reorganization in adult monkey cortex after peripheral nerve injury. Proc Natl Acad Sci USA 88:6976-6980.

Garraghty PE, Sur M (1990) Morphology of single intracellularly stained axons terminating in area $3 \mathrm{~b}$ of macaque monkeys. J Comp Neurol 294:583-593.

Garraghty PE, Hanes DD, Florence SL, Kaas JH (1994) Pattern of peripheral deafferentation predicts reorganizational limits in adult primate somatosensory cortex. Somatosens Mot Res 11:109-117.

Huntley GW, Jones EG (1991) Relationships of intrinsic connections to forelimb movement representations in monkey motor cortex: a correlative anatomic and physiological study. J Neurophysiol 66:390-413.

Jones EG, Powell TPS (1969) Connexions of the somatic sensory cortex of the rhesus monkey. I. Ipsilateral cortical connexions. Brain 92:477-502.

Jones EG, Coulter JD, Hendry SHC (1978) Intracortical connectivity of architectonic fields in the somatic sensory, motor and parietal cortex of monkeys. J Comp Neurol 181:291-348.

Jones EG, Friedman DP (1982) Projection pattern of functional compo- nents of thalamic ventrobasal complex on monkey somatosensory cortex. J Neurophysiol 48:521-544.

Jones EG, Friedman DP, Hendry SHC (1982) Thalamic basis of place- and modality-specific columns in monkey somatosensory cortex: a correlative anatomical and physiological study. J Neurophysiol 48:545-568.

Jones EG, Hendry SHC, Brandon C (1986a) Cytochrome oxidase staining reveals functional organization of monkey somatosensory thalamus. Exp Brain Res 62:438-442.

Jones EG, Schwark HD, Callahan PA (1986b) Extent of the ipsilateral representation in the ventral posterior medial nucleus of the monkey thalamus. Exp Brain Res 63:310-320.

Kaas JH (1991) Plasticity of sensory and motor maps in adult mammals. Annu Rev Neurosci 14:137-167.

Kaas JH, Nelson RJ, Sur M, Lin C-S, Merzenich MM (1979) Multiple representations of the body within the primary somatosensory cortex of primates. Science 204:521-523.

Kerr FWL (1972) Central relationships of trigeminal and cervical primary afferents in the spinal cord and medulla. Brain Res 43:561-572.

Kerr FWL, Kruger L, Schwassmann HP, Stern R (1968) Somatotopic organization of mechano-receptor units in the trigeminal nuclear complex of the macaque. J Comp Neurol 134:127-143.

Krubitzer LA, Kaas JH (1990) The organization and connections of somatosensory cortex in marmosets. J Neurosci 10:952-974.

Krubitzer LA, Calford MB, Schmid LM (1993) Connections of somatosensory cortex in megachiropteran bats: the evolution of cortical fields in mammals. J Comp Neurol 327:473-506.

Krubitzer LA, Clarey J, Tweedale R, Elston G, Calford MB (1995) A redefinition of somatosensory areas in the lateral sulcus of macaque monkeys. J Neurosci 15:3821-3839.

Lund JP, Sun G-D, Lamarre Y (1994) Cortical reorganization and deafferentation in adult macaques. Science 265:546-548.

Manger PR, Woods TM, Jones EG (1996) Representation of face and intraoral structures in area $3 \mathrm{~b}$ of macaque somatosensory cortex. J Comp Neurol 371:513-521.

Merzenich MM, Nelson RJ, Stryker MP, Cynader MS, Schoppmann A, Zook JM (1984) Somatosensory cortical map changes following digit amputation in adult monkeys. J Comp Neurol 224:591-605.

Nelson RJ, Sur M, Felleman SJ, Kaas JH (1980) Representations of the body surface in postcentral parietal cortex of Macaca fascicularis. J Comp Neurol 192:611-643.

Petit MJ, Schwark HD (1993) Receptive field reorganization in dorsal column nuclei during temporary denervation. Science 262:2054-2058.

Pons TP, Wall JT, Garraghty PE, Cusick CG, Kaas JH (1987) Consistent features of the representation of the hand in area $3 \mathrm{~b}$ of macaque monkeys. Somatosens Res 4:309-331.

Pons TP, Garraghty PE, Ommaya K, Kaas JH, Taub E, M Mishkin M (1991) Massive cortical reorganization after sensory deafferentation in adult macaques. Science 252:1857-1860.

Powell TPS, Mountcastle VB (1959a) The cytoarchitecture of the postcentral gyrus of the monkey Macaca mulatta. Bull Johns Hopkins Hosp 105:108-131.

Powell TPS, Mountcastle VB (1959b) Some aspects of the functional organization of the cortex of the postcentral gyrus of the monkey: a correlation of findings obtained in a single unit analysis with cytoarchitecture. Bull Johns Hopkins Hosp 105:133-162.

Rausell E, Jones EG (1991a) Histochemical and immunocytochemical compartments of the thalamic VPM nucleus in monkeys and their relationship to the representational map. J Neurosci 11:201-225.

Rausell E, Jones EG (1991b) Chemically distinct compartments of the thalamic VPM nucleus in monkeys relay principal and spinal trigeminal pathways to different layers of the somatosensory cortex. J Neurosci 11:226-237.

Rausell E, Jones EG (1995) Extent of intracortical arborization of thalamocortical axons as a determinant of representational plasticity in monkey somatic sensory cortex. J Neurosci 15:4270-4288.

Rausell E, Cusick CG, Taub E, Jones EG (1992) Chronic deafferentation in monkeys differentially affect nociceptive and non-nociceptive pathways distinguished by specific calcium-binding proteins and downregulates $\gamma$-aminobutyric acid type A receptors at thalamic levels. Proc Natl Acad Sci USA 89:2571-2575.

Recanzone GH, Merzenich MM, Dinse HR (1992a) Expansion of the cortical representation of a specific skin field in primary somatosensory cortex by intracortical microstimulation. Cereb Cortex 2:181-196.

Recanzone GH, Merzenich MM, Jenkins WM, Grajski KA, Dinse HR 
(1992b) Topographic reorganization of the hand representation in cortical area $3 \mathrm{~b}$ of owl monkeys trained in a frequency-discrimination task. J Neurophysiol 67:1031-1056.

Roberts TS, Akert K (1963) Insular and opercular cortex and its thalamic projection in Macaca mulatta. Schweiz Arch Neurol Neurochir Psychiatr 92:1-43.

Robinson CJ, Burton H (1980) Somatotropic organization on the second somatosensory area of M. fascicularis. J Comp Neurol 192:43-67.

Shanks MF, Pearson RCA, Powell TPS (1985) The ipsilateral corticocortical connexions between the cytoarchitectonic subdivisions of the primary somatic sensory cortex in the monkey. Brain Res Rev 9:67-88.

Sherrington C (1939) On the distribution of the sensory nerve roots. In:
Selected writings of Sir Charles Sherrington (Denny-Brown D, ed), pp 31-93. London: Hamish Hamilton Medical Books.

Wall JT, Kaas JH, Sur M, Nelson RJ, Felleman DJ, Merzenich MM (1986) Functional reorganization in somatosensory cortical areas 3b and 1 of adult monkeys after median nerve repair: possible relationships to sensory recovery in humans. J Neurosci 6:218-233.

Woolsey CN (1958) Organization of somatic sensory and motor area of the cerebral cortex. In: Biological and biochemical bases of behavior (Harlow HF, Woolsey CN, eds), pp 63-81. Madison, WI: University of Wisconsin.

Woolsey CN, Marshall WH, Bard P (1942) Representation of cutaneous tactile sensibility in the cerebral cortex of the monkey as indicated evoked potentials. Bull Johns Hopkins Hosp 70:399-441. 